\title{
Ecological Importance of Rhizophoraceae - A true mangrove family
}

\author{
A. Arunprasath, M. Gomathinayagam* \\ Department of Botany, Annamalai University, Annamalainagar-608 002 Tamilnadu, India \\ Corresponding Author E-mail: gomsnayagam@yahoo.com
}

Keywords: Rhizophoraceae, Bruguiera, Ecology, Ceriops, wood, medicinal.

\begin{abstract}
Mangroves are various types of trees up to medium height and shrubs that grow in saline coastal sediment habitats in the tropics and subtropics mainly between latitudes $25^{\circ} \mathrm{N}$ and $25^{\circ} \mathrm{S}$. Mangrove ecosystems represent natural capital capable of producing a wide range of goods and services for coastal environments and communities and society as a whole. Some of these outputs, such as timber, are freely exchanged in formal markets. Value is determined in these markets through exchange and quantified in terms of price. Particularly the mangroves of Rhizophoraceae have so many ecological importances. Breeding and nursery grounds for a number of marine organisms including the commercially important shrimp crab and fish species. Mangrove trees are also used for house building, furniture, transmission as well as telephone poles and certain household items. Mangrove trees have been the source of firewood in India since ancient time. Because of the high specific gravity of rhizophoraceous wood, the species of Rhizophora, Kandelia, Ceriops and Bruguiera are preferred for firewood.
\end{abstract}

\section{INTRODUCTION}

The term "mangrove" has been applied historically to plants which live in muddy, wet soil in tropical or subtropical tidal waters. In the nineteen sixties the term "mangal" was used for a community of mangrove plants and the term "mangrove" for the plant species making up the forest. The terminology has tended to fall into disuse recently and term such as "mangrove forest", "tidal forest" and "coastal woodland" have begun to appear from groups of evergreen plants possessing marked similarities in their physiological characteristics and structural adaptations to habitats influenced by the tides. The scientific literature is divided broadly into studies of the biology of individual species of plants or animals in the mangroves and the study of communities that may involve just plants or the relationship between plants and animals. The present intention is to sketch the most important features of mangroves and mangrove communities in such a way that they can be understood by the interested user.

Mangrove trees have special adaptation to live in saline habitats. The specialized seeds of mangroves are tough, float and travel great distances in salt water and take root far from its parent tree. The seeds germinate and grow into seeding right on the parent tree. During this time, they acquire the carbohydrates they need later to grow on their own. The mangrove tree eventually drops its seedlings, where they take root in the mud below or are swept out by the tide. The mangrove trees have unique biological adaptation to survive this marine environment, including reproductive biology, salt tolerance, and growth form. They are well adapted to anoxic sediments. They produce aerial and tap roots which filter out the salt in the brackish water they grow in and support roots which grow directly into the mud to anchor them. Breathing roots allow them to survive in anoxic sediments. Buttresses and above ground roots enable them to grow in unstable mud flats. Their foliage removes excess salt from the sap and conserves water to cope with periods of high salinity.

Rhizophoraceae is a tropical and sub-tropical plant group. This family comprise of 16 genus with 120 species consist of either trees or shrubs, are distributed in the Old World, as in East Africa, India, South East Asia and Australia . This family was classified to be under the order Myrtales at the beginning, later placed in its own order the Rhizophorales based on a more detailed morphological character of the flower and leaf. There are two tribes which are Gynotrocheae and Rhizophoreae, but Rhizophoreae is a more important tribe based on the species stand in the 
mangrove. Rhizophoreae which is a plant group of the mangrove and also known as 'Mangrove Rhizophoraceae' comprises of four genera that are Rhizophora, Bruguiera, Ceriops and Kandelia

In Rhizophoraceae, the flowering and fruiting occur vary species to species. The flowers with red sepals and brown petals are quite conspicuous against the foliage. The mature buds which are ready for opening require external tripping by birds and in the absence of bird visits, the buds remain as they are and fall off subsequently. Each petal encloses two stamens and behaves independently; the bird tripping of mature bud does not lead to simultaneous burst of stamens from each petal. This independent opening of petals is a unique floral device evolved for receiving multiple visits by birds. The birds involved in floral tripping are sunbirds

(Nectarinia asiatica and $N$. zeylonica). This indicates that Rhizophoraceae disperses pollen to its neighbouring or distantly spaced trees through floral explosion by using bird species.

\section{ROOT OF RHIZOPHORACEAE:}

\section{Stilt roots}

Common to the mangrove species of genus Rhizophora, these stilt roots are branched, looping aerial prop roots that arise from the trunk and lower branches of the trees. They function to rovide aerial ventilation but more importantly provide added support to the lower part of the trunk as the name implies. The number of roots and complexity of root structure are hypothesized to be the response to the intensity of wind and wave stresses.

\section{Pneumatophores}

These visible erect lateral branches of the horizontal cable roots growing underground are common to the species of Avicennia and Sonneratia. The pencil-like pneumatophores are spaced at regular intervals along the primary root cable.

\section{Root knees}

These are common to Bruguiera and Ceriops, where the horizontal cable component of the root system surfaces periodically while growing away from the tree. Loops are formed by the surfacing roots before continuing horizontal growth.

\section{Some Important Values of Rhizophoraceae:}

Rhizophoraceae forests and estuaries are the breeding and nursery grounds for a number of marine organisms including the commercially important shrimp, crab and fish species. Hence, loss of mangroves not only affects us indirectly but there are direct economic repercussions through loss of fishing industry. Some trees of Rhizophoraceae are also used for house building, furniture, transmission as well as telephone poles and certain household items. When these activities are managed appropriately it is possible to derive timber products from mangrove forests without significant environmental degradation, and while maintaining their value as a nursery and a source of food for commercial capture fisheries. In many coastal areas including Gulf of Kutch, these trees are a substitute for fodder. Thus mangroves reduce pressures from the scarce pasturelands. Tannin is extracted from the bark of some mangrove species like Rhizophora mucronata, Bruguiera gymnorrhiza and Ceriops tagal. Indian mangrove trees have $35 \%$ tannin in their bark, which is higher compared to other countries. Extracts from mangrove bark are used by Indian fishermen to dye their fishing net and enhance its durability. Mangrove trees have been the source of firewood in India since ancient time. Because of the high specific gravity of Rhizophoraceous wood, the species of Rhizophora, Kandelia, Ceriops and Bruguiera are preferred for firewood. Rhizophora spp. Are used for brick-burning. Bruguiera spp. Are also used to make poles Above all, Mangroves are now looked after by scientists as saviors in the today's scenario of global warming. We all know that most of the coastal areas throughout the world are going to be affected by sea level rise due to global warming. The effects of which are already visible. Therefore, when most of the coastal areas will be flooded, mangroves can possibly provide a gene bank for cultivating salt tolerant species of crops which could be our future resource. 


\section{Rhizophoraceae in Coastal protection:}

Rhizophoraceae provide nursery habitat for many wildlife species, including commercial fish and crustaceans, and thus contribute to sustaining the local abundance of fish and shellfish populations. Seventy-five percent of the game fish and ninety percent of the commercial species are dependent on mangrove ecosystems. Mangrove systems support a range of wildlife species including crocodiles, birds, tigers, deer, monkeys and honey bees. Many animals find shelter either in the roots or branches of mangroves. Mangroves serve as rookeries, or nesting areas, for coastal birds such as brown pelicans and roseate spoonbills. Many migratory species depend on mangroves for part of their seasonal migrations.

Rhizophoraceae maintain coastal water quality by abiotic and biotic retention, removal, and cycling of nutrients, pollutants, and particulate matter from land-based sources, filtering these materials from water before they reach seaward coral reef and seagrass habitats. Toxins and nutrients can be bound to sediment particles or within the molecular lattice of clay particles and are removed during sediment deposition. Compared with the expense of constructing a wastewater treatment plant, mangroves are commonly selected as receiving areas of effluent. Increasingly the notion of specifically constructed mangrove wetlands is being adopted and used for treatment of aquaculture and sewage effluents. The existence and health of coral reefs are dependent on the buffering capacity of these shoreward ecosystems, which support the oligotrophic conditions needed by coral reefs to limit overgrowth by algae.

Mangroves supply nutrients to adjacent coral reef and seagrass communities, sustaining these habitats' primary production and general health. As a result of their intricately entangled aboveground root systems, mangrove communities protect shorelines during storm events by absorbing wave energy and reducing the velocity of water passing through the root barrier. Wave energy may be reduced by 75 per cent in the wave's passage through 200 metres of mangrove. Protecting mangroves sustains natural protection, and is less expensive than seawalls and similar erosion control structures, which can increase erosion in front of the structure and at adjacent properties. The tsunami has provided an opportunity to illustrate that healthy mangroves serve as a natural barrier against massive waves - protecting infrastructure developments and saving lives.

\section{CONCLUSION}

This study concludes the ecological importance of Rhizophoraceae family. This family have so many ecological importances like Breeding and nursery grounds for a number of marine organisms including the commercially important shrimp crab and fish species. Mangrove trees are also used for house building, furniture, transmission as well as telephone poles and certain household items. Mangrove trees have been the source of firewood in India since ancient time. Because of the high specific gravity of Rhizophoraceous wood, the species of Rhizophora, Kandelia, Ceriops and Bruguiera are preferred for firewood.

\section{References}

[1] Bhosale, L.J. and Mulik, N.G. (1991). In: David, N. S. and Mohammed, S. (Eds.) Proceedings on International Seed Symposium, Jodhpur, India, pp. 201-205.

[2] Anonymous 1984. A profile of the Indian Mangrove. Bakawan Newsletter 3: 10.

[3] Banerjee, L.K., A.R.K. Sastry \& M.P. Nayar. 1989. Mangrove in India, Identification Manual. Botanical Survey of India, Govt. of India.

[4] Blasco, F. 1975. The Mangroves in India. Institute Francais de Pondicherry, Inde, Sri Aurobinda Ashram, India.

[5] Blasco, F., S. Chanda \& G. Thanikaimoni. 1975. Main characteristics of Indian Mangroves. pp. 71-83. In: 
[6] G. Walsh, S.C. Snedaker \& H.J. Teas (eds.) Proceedings of International Symposium on Biology and Management of Mangroves. Institute of Food and Agricultural Science, University of Florida, Florida.

[7] Blasco, F. 1977. Outline of ecology, botany and forestry of the mangals of the Indian subcontinent. pp. 241-260.

[8] Blasco, F. \& M. Aizpuru. 1997. Classification and evolution of the mangroves of India. Tropical Ecology 38: 357-374 